\title{
(RE) SIGNIFICANDO O BRINCAR NA EDUCAÇÃO INFANTIL A PARTIR DA TEORIA HISTÓRICO-CULTURAL
}

\author{
(RE) SIGNIFICANDO EL BRINCAR PARA LA EDUCACIÓN SEGÚN LA \\ TEORÍA HISTÓRICO-CULTURAL
}

\section{A DIFFERENT MEANING TO PLAY THROUGH CULTURAL HISTORICAL THEORY}

\author{
Mariana de Oliveira FARIA ${ }^{1}$ \\ Alessandra Arce $\mathrm{HAI}^{2}$
}

RESUMO: O presente artigo resulta de trabalho de pesquisa onde buscou-se apreender, compreender e analisar as possíveis contribuições de autores contemporâneos internacionais do campo da Teoria Histórico-cultural para a Educação Infantil. A brincadeira de papéis sociais foi o objeto escolhido para essa aproximação. A pesquisa caracterizou-se pela análise bibliográfica a partir da produção de autores que trabalham com a educação de crianças menores de 5 anos, procedendo investigações tanto em ambientes escolares como não escolares. As obras de duas autoras pelo conjunto significativo de produções foram escolhidas para análise: Marianne Hedegaard e Marylin Fleer. Dois conceitos apresentados pelas autoras são analisados no artigo: 'ambientes de atividades' e 'jogo conceitual'. Ambos corroboram para a compreensão do papel que a brincadeira de papéis sociais possui para o desenvolvimento infantil, atribuindo novos significados ao mesmo. Portanto, esses conceitos são apresentados e exemplificados, objetivando pensarmos caminhos para o brincar na Educação Infantil brasileira.

PALAVRAS-CHAVE: Brincar de faz-de-conta. Educação infantil. Psicologia históricocultural.

RESUMEN: El presente artículo resulta de trabajo de investigación donde se buscó aprehender, comprender y analizar las posibles contribuciones de autores contemporáneos internacionales del campo de la Teoría Histórico-cultural para la Educación Infantil. La broma de roles sociales fue el objeto de estudio elegido para este enfoque. La investigación se caracterizó por el análisis bibliográfico a partir de la producción de autores que trabajan con la educación de niños menores de 5 años, que realizan investigaciones en ambientes escolares y no escolares. Los trabajos de dos autores fueron elegidos por el conjunto considerable de sus producciones: Marianne Hedegaard y Marylin Fleer. En el artículo se analizan dos conceptos presentados por las autoras: 'ambientes de actividad' y 'juego conceptual'. Ambos corroboran la comprensión del papel que el juego de roles sociales dispone para el desarrollo infantil, atribuyendo nuevos significados al mismo. Por lo tanto,

${ }^{1}$ Universidade Federal de São Carlos (UFSCar), São Carlos - SP - Brasil. Doutoranda do Programa de PósGraduação em Educação. OrcID: https://orcid.org/0000-0002-7064-5379. E-mail: ma.ofaria9@gmail.com

${ }^{2}$ Universidade Federal de São Carlos (UFSCar), São Carlos - SP - Brasil. Professora do Departamento de Educação. OrcID: https://orcid.org/0000-0002-9275-1201. E-mail: alessandra.arce@gmail.com 
esos conceptos son presentados y ejemplificados, con el objetivo de pensar caminos para jugar en la Educación infantil brasileña.

PALABRAS CLAVE: Juego de hacer de cuenta. Crianza del ñino. Psicología históricocultural.

ABSTRACT: This article results of a research work where we sought to understand and analyze the possible contributions of contemporary international authors from the field of Cultural Historical Theory for Early Childhood Education. Social role play was the object chosen for this approach. The research was characterized by bibliographical analysis based on the production of authors who work with the education of children under 5 years, carrying out investigations in both school and non-school environments. The works of two authors for the significant set of productions were chosen for analysis: Marianne Hedegaard and Marylin Fleer. Two concepts presented by the authors are analyzed in the article: 'activity settings' and 'conceptual play'. Both concepts corroborate to understand the important contribution that social role play has for child development, attributing new meanings to it. Therefore, these concepts are presented and exemplified, aiming to think ways to work with play in the Brazilian Early Childhood Education.

KEYWORDS: Pretend play. Early childhood education. Historic-cultural psychology.

\section{Introdução}

Este artigo é um recorte de pesquisa desenvolvida na qual buscou-se apreender, compreender e analisar as possíveis contribuições dos trabalhos investigativos elaborados por autores contemporâneos internacionais dentro do campo da Teoria Histórico-cultural para a Educação Infantil. Nossa análise centrou-se na brincadeira de papéis sociais.

Escolhemos a brincadeira como categoria de análise pois ela é considerada um dos eixos do trabalho na Educação Infantil no Brasil, de acordo com o Referencial Curricular Nacional para a Educação Infantil (1998) e com as Diretrizes Curriculares Nacionais para a Educação Infantil (2010). Portanto, consideramos inequívoca a necessidade de compreendermos como a brincadeira tem sido pensada a partir da abordagem Históricocultural na atualidade, sem desconsiderar as contribuições dos clássicos dessa matriz teórica.

$\mathrm{Na}$ pesquisa realizada trabalhamos com os seguintes autores internacionais contemporâneos: Seth Chaiklin (professor na UCC/Dinamarca), Marilyn Fleer (Universidade de Melbourne/Austrália), Marianne Hedegaard (professora emérita da Universidade de Copenhagen/Dinamarca), Bert Van Oers (professor emérito na Free University Amsterdam/Holanda), Elena Kravtsova (presidente do Instituto Vygotsky) e Gennádi Kravtsov. 
Tais autores têm continuado as investigações de L. S. Vygotsky, D. B. Elkonin, A. N. Leontiev e outros teóricos; todos eles centram-se na criança menor de cinco anos a partir da Teoria Histórico-cultural, realizando pesquisas com crianças tanto em salas de aula como no ambiente familiar, trazendo contribuições acerca do desenvolvimento da criança e possibilidades de trabalho na Educação Infantil. Além de apresentarem uma extensa produção bibliográfica também participam ativamente da Sociedade Internacional para Pesquisa Cultural e da Atividade (International Society for Cultural and Activity Research - ISCAR).

A metodologia empregada na pesquisa foi de caráter teórico-bibliográfico. Como se tratou de um estudo de natureza teórica sobre a Teoria Histórico-cultural e as contribuições teórica e metodológicas produzidas por autores internacionais, trabalhamos com a leitura e análise de alguns artigos e livros dos autores escolhidos.

Entre os autores analisados, Marilyn Fleer é que mais aborda a questão da brincadeira no espaço da Educação Infantil. O conceito de 'ambientes de atividades' elaborado por Marianne Hedegaard também é fundamental para a compreensão das proposições de Marilyn Fleer, por isso, este artigo se centrará nas contribuições dessas duas autoras.

Para tanto, subdividimos o texto em três partes: iniciamos com a compreensão de Marilyn Fleer e Mariane Hedegaard acerca dos processos de desenvolvimento e aprendizagem da criança onde daremos ênfase no conceito de 'ambientes de atividades'; em seguida, focamos na proposta do 'jogo conceitual' elaborado por Marilyn Fleer; por fim, procedemos nossa conclusão fazendo uma contraposição com as propostas dos autores contemporâneos apresentadas e as ideias propagadas no contexto brasileiro, a partir dos documentos norteadores da Educação Infantil.

Com este trabalho, não defendemos que as proposições ou práticas descritas aqui pertencentes a outros países sejam transpostas para nosso contexto, apenas buscamos subsídios para (re) pesarmos o trabalho pedagógico da Educação Infantil, com o foco na brincadeira, a partir das contribuições dos autores contemporâneos da Teoria Históricocultural analisados.

Por se tratar de um recorte de pesquisa, as ideias dos autores estudados serão apresentadas de forma resumida e nossa atenção se voltará para o papel que a brincadeira ocupa (ou deveria ocupar) na prática pedagógica da Educação Infantil. 


\section{Os 'ambientes de atividades' e o desenvolvimento da criança}

Antes de apresentarmos as possibilidades da brincadeira na Educação Infantil, abordaremos alguns pontos necessários para pensarmos a criança presente nesse espaço, embasadas em Fleer; Hedegaard (2013), trabalhando com o conceito da existência de 'ambientes de atividades' (activity settings). A partir desse conceito as autoras ampliam a visão sobre o desenvolvimento infantil, apontando como as instituições, práticas sociais, aprendizagem e a brincadeira estão entrelaçadas nesse processo. Assim conseguimos nos aproximar da criança, apreendendo a completude de sua formação e desenvolvimento. Ao mesmo tempo, ao fazê-lo, as autoras delineiam a função específica da Educação Infantil: a aprendizagem científica; tal ideia também é abordada em Chaiklin; Hedegaard (2013).

O desenvolvimento da criança é visto como uma unidade dialética entre os fatores biológicos e históricos; tal unidade permite que as funções psicológicas superiores sejam desenvolvidas. Hedegaard $(2004,2014)$ afirma que a criança se desenvolve por meio da inserção em práticas sociais das diferentes instituições da sociedade que lhe fornecem 'ambientes de atividade' diversos com demandas específicas. O desenvolvimento, portanto, se dá na relação entre a criança e o meio social, dependendo não apenas da criança, mas das interações estabelecidas entre ela e as condições históricas e culturais.

As novas formações psicológicas da criança decorrem da contradição existente entre as ações que a criança é capaz de realizar, a partir das funções psicológicas já estabelecidas, com aquelas ações que ainda não possui as funções necessárias para atendê-las. As atividades que a criança se envolve e as interações que estabelecem para superar essa contradição contribuem para a consolidação das novas funções psicológicas.

Fleer; Hedegaard (2013) explicam esse processo trazendo o conceito de situação social do desenvolvimento, ressaltando a importância das diferentes instituições sociais e como essas são influenciadas por outras práticas e demandas sociais. Os diferentes 'ambientes de atividades' construídos pelas diversas instituições sociais das quais a criança participa se entrelaçam, formando uma grande rede na qual a criança transita em ziguezague, sendo influenciada e ao mesmo tempo influenciando esses mesmos ambientes com o que leva, traz, sintetiza, analisa e constrói ao experimentá-los e vivenciá-los.

De acordo com Fleer e Hedegaard (2013) a situação social do desenvolvimento pode ser entendida como uma unidade entre o ambiente que a criança conhece, seu motivo orientador e sua relação com o meio, sendo que 
essa relação reflete o período da idade de desenvolvimento da criança. $\mathrm{O}$ período da idade de desenvolvimento da criança não é a mesma coisa que a idade biológica da criança. A idade de desenvolvimento da criança ou período da idade reflete a relação qualitativa da criança com seu ambiente (meio) e depende da orientação motivacional da criança. Essa relação qualitativa da idade específica é conceituada por Elkonin como o motivo principal da criança (FLEER; HEDEGAARD, 2013, p. 07, tradução nossa, grifos do autor).

Diante disso, podemos afirmar que as novas formações psicológicas estão presentes nos períodos etários a partir da estrutura interna dos indivíduos, das contradições e exigências demandadas para a criança para executar determinadas atividades, presentes nos diversos 'ambientes de atividades' nos quais a criança participa.

A escola é uma das instituições na qual as crianças participam no decorrer de sua vida. Ao entrar na escola surgem mudanças nas demandas e na posição social da criança. A situação social de desenvolvimento também se altera, ao passo que as crianças respondem às novas demandas e desenvolvem novos motivos orientadores.

Os valores sociais desenvolvidos historicamente apontam para o que é esperado em cada idade de desenvolvimento, apresentando-se como demandas nas práticas sociais, ao atendê-las criam-se motivos orientadores e pessoais. As crianças passam a conhecer as demandas presentes nas instituições, e a partir delas, orientam-se para seguir as atividades esperadas.

Portanto, ao pensarmos os diversos 'ambientes de atividades' é necessário que reconheçamos a importância do processo de mediação no desenvolvimento psíquico, sobretudo em relação ao papel da aprendizagem, do ensino e do uso de ferramentas culturais, considerando uma unidade entre o aspecto material e mental. Essa unidade é importante para o entendimento do ser humano como seres culturais inseridos nas práticas sociais, pois, para Hedegaard (2004), o ser humano influencia e também é influenciado pelas práticas sociais.

Segundo a autora, do mesmo modo que os seres humanos aprendem os procedimentos adequados para o uso e produção de ferramentas específicas, aprendem também determinados procedimentos sociais adequados na interação e na interpretação dos elementos presentes nas práticas de diferentes instituições sociais. O contexto, portanto, é uma das condições para a aprendizagem.

Assim, é possível entender que a aprendizagem no espaço escolar proporciona à criança procedimentos para lidar com uma área específica de objetos e ferramentas, enquanto que a aprendizagem no ambiente familiar, por exemplo, relaciona com outros procedimentos e modos de agir. Em outras palavras, Hedegaard (2004) traz a ideia de que dentro das 
diferentes instituições há distintas práticas sociais, essas práticas demandam da criança determinadas disposições e habilidades e a aprendizagem se faz presente na interação estabelecida entre a criança e as tradições culturais realizadas nas práticas das diversas instituições sociais, ou seja, nas demandas que os diversos 'ambientes de atividades' fazem à criança.

As contribuições de Fleer e Hedegaard (2013) acordam com nossa intenção de (re) pensarmos a educação infantil. Com os resultados das pesquisas desenvolvidas e apresentadas pelas autoras amplia-se nossa visão acerca do desenvolvimento da criança presente nesse espaço, pois é possível compreendermos que a formação e os processos de aprendizagem da criança não se darão apenas no ambiente escolar.

Conforme apontado, a criança participa de diferentes instituições sociais como: a família, a escola, os clubes de recreação, igrejas, etc; que contribuem com a sua formação e desenvolvimento. Diante disso, faz-se necessário que o professor tenha essa percepção e busque compreender melhor a criança com a qual está trabalhando, ou seja, entender essa criança ao ingressar no espaço escolar com hábitos, valores e comportamentos trazidos de outras instituições.

Para tanto, é preciso que o professor tenha clareza tanto do seu papel enquanto profissional, quanto da função da Educação Infantil de promover o desenvolvimento das crianças por meio da aprendizagem científica. Em outras palavras, a prática escolar incluindo, portanto, a Educação Infantil, diferencia-se das demais instituições sociais por apresentar essa especificidade.

O entendimento mais amplo e completo da criança também permite que o professor da Educação Infantil não aja conforme pré-conceitos estabelecidos por (in) compreensões superficiais e imediatistas acerca do comportamento infantil, por exemplo, de atribuir determinadas patologias ou dificuldades que são práticas comuns no ambiente familiar.

A partir do exposto, ao apresentarmos essa compreensão mais ampla dos processos de aprendizagem e desenvolvimento da criança, pensando no contexto da Educação Infantil, a seguir trataremos como no 'ambiente de atividades' construído, pensado, planejado da escola de Educação Infantil a brincadeira pode/deve ser geradora de conhecimentos científicos e ao mesmo tempo exercício livre para a criança construir conceitos e percepções do mundo. 


\section{O jogo conceitual (conceptual play)}

Neste item apresentaremos a proposta do jogo conceitual desenvolvida por Marilyn Fleer para exemplificar algumas possibilidades de como a brincadeira pode ser contemplada no espaço da Educação Infantil. É válido ressaltarmos mais uma vez que não defendemos a aplicação idêntica de tal proposta nas pré-escolas brasileiras, uma vez que traremos um modelo teórico, e, embora Marilyn Fleer aponte alguns exemplos em seus trabalhos, sua materialização depende das condições de cada contexto.

Nossa intenção é possibilitar ao leitor maneiras para (re) pensarmos a Educação Infantil ampliando as possibilidades de ação e intervenção do professor na atividade lúdica, visando contribuir com a aprendizagem científica, a partir da formação de conceitos.

Para Fleer (2010), o jogo conceitual representa uma teoria e um modelo pedagógico que utiliza a brincadeira como fator fundamental no desenvolvimento conceitual das crianças na Educação Infantil. O foco de tal proposta está na construção do conhecimento teórico e por estar embasado na perspectiva Histórico-cultural, essa proposta de brincadeira possibilita que a criança crie uma situação imaginária e a partir dela seja capaz de mudar os significados dos objetos e de suas ações, movendo-se para dentro e para fora das situações imaginárias criadas.

Fleer (2010) ancorada na Teoria Histórico-cultural afirma que a formação conceitual se dá em dois níveis: o cotidiano e o acadêmico (ou científico). No nível cotidiano a aprendizagem dos conceitos surge do contato direto com o mundo, o que leva a compreensões de caráter intuitivo sobre as coisas, ou seja, nesse nível a criança pode interagir com o mundo real sem ter uma compreensão científica dos fenômenos, situações e ações. Já no nível acadêmico (ou científico) é preciso alguma forma sistematizada para ensinar esses conceitos para a criança. Para a autora, quando os conceitos científicos ou acadêmicos são introduzidos fora das experiências cotidianas da criança, eles não fazem tanto sentido a ela, logo, os conceitos científicos e as experiências são importantes para a aprendizagem e desenvolvimento da criança e devem ser pensados dialeticamente.

A brincadeira relaciona-se diretamente com as experiências cotidianas da criança e depende, portanto, das condições sociais oferecidas. Mesmo as regras presentes nas situações imaginárias são derivadas do mundo real, estabelecendo uma relação dialética entre imaginação e realidade.

Diante disso, Fleer (2010) entende que propostas pedagógicas baseadas no brincar apresentam grande potencial para criar contextos nos quais a cognição cotidiana da criança 
possa ser evidenciada, representando um mecanismo para que a brincadeira seja promovida como um lócus para a introdução de novos conceitos.

No entanto, é preciso que o professor compreenda a criança presente nesse ambiente de uma maneira mais ampla, conforme exposto no item anterior: entender que a criança se desenvolve por meio das práticas sociais, dos 'ambientes de atividades' presentes nos diferentes espaços institucionais e a Educação Infantil precisa cumprir com sua função de aprendizagem científica.

Partindo da ideia que a criança pode experimentar o mundo em que vive sem necessariamente ter consciência dele, isto é, estar em interação com o ambiente físico sem compreender os conceitos científicos presentes, notamos a importância do desenvolvimento conceitual da criança para que essa possa compreender melhor a realidade em que está inserida, ampliando-se, também, as possibilidades de ação nessa realidade.

Contudo, para que o professor consiga relacionar os conceitos cotidianos e científicos da criança promovendo de fato uma construção conceitual, algumas conexões são necessárias entre ele e a criança.

Nos exemplos trazidos em Fleer (2010), essas conexões são mais evidentes. Em uma das situações descritas uma criança está brincando na área externa da pré-escola com óleo, areia, água e outros objetos, afirmando que estava preparando um milk-shake. A professora interviu na brincadeira e perguntou como a areia, a água e o óleo tinham se separado na mistura, mas a criança não se interessou pelo questionamento da professora, já que estava envolvida na situação imaginária de preparar um milk-shake.

Notou-se que por mais que a professora tenha tentado focar a atenção da criança para os materiais (água, óleo e areia), ela a ignorava. A ação da criança não estava sendo determinada pelos objetos reais, impossibilitando que a questão das propriedades do óleo, areia e água fossem abordadas, ou seja, a professora não conseguiu introduzir novos conceitos para a criança nessa situação pois não foi suficiente apenas disponibilizar determinados materiais e/ou objetos para que a criança se interessasse em descobrir novos conhecimentos e conceitos acerca dos mesmos.

Ao contrário do que a professora imaginava, o foco da criança voltou-se para a ação de cozinhar e não para as propriedades dos materiais. A criança brincava a partir desse motivo, estava conscientemente analisando conceitos cotidianos e exibindo um forte objeto/motivo (object-motive) para a imitação da vida cotidiana.

Tal situação ilustra como a brincadeira revela tanto aspectos do mundo real quanto da situação imaginária, ou seja, das experiências e conhecimentos acumulados. Para Fleer 
(2010), a professora não conseguiu mudar o foco conceitual da criança, pois se encontravam em mundos conceituais paralelos.

Percebemos com esse exemplo que a brincadeira da criança no espaço pré-escolar não contribuiu diretamente para a compressão e apreensão de novos conceitos, conforme pretendia a professora. Fleer (2010) aponta para a necessidade e importância de se estabelecer uma intersubjetividade contextual e conceitual (conceptual and contextual intersubjectivity) entre a criança e o professor. Nessa relação, o professor estrutura pedagogicamente a brincadeira por meio de uma situação imaginária baseada nos conceitos cotidianos da criança, criando um espaço conceitual compartilhado (shared conceptual space), possibilitando o pensamento compartilhado sustentado (sustained shared thinking).

Em contrapartida, em outra situação trazida por Fleer (2010) uma professora e sua assistente foram capazes de estabelecer essa relação com o aluno e, ao introduzir novos conceitos científicos, levaram o garoto a pensar teoricamente.

O exemplo descreve uma pré-escola com grande área externa, várias plantas e insetos. Um dos alunos observava bastante esse ambiente, fazendo com a que a professora voltasse sua atenção para essa atitude; ela também sabia que os pais desse aluno eram cientistas.

Em uma determinada situação o aluno ficou muito aflito ao ver uma espécie de formiga dentro da sua escola, ao ser questionado pela professora sobre o motivo da sua preocupação, ele disse que estava com medo que uma das crianças fosse mordida pela formiga ou que a formiga fosse ferida por elas.

Diante dessa situação, a professora propôs que eles realocassem a formiga para um lugar mais apropriado. O garoto identificou uma característica visual dessa formiga, provavelmente com os conhecimentos que já possuía por meio do seu ambiente familiar, percebendo que ela não deveria estar naquele local. Ele sabia que uma das características daquela espécie de formiga era suas pinças afiadas que poderiam ferir as crianças.

Com essa situação, a professora foi capaz de apoiar o pensamento teórico do garoto, na medida em que ouviu atentamente suas preocupações para colocar a formiga em outro lugar. Além disso, visando elevar o nível de pensamento a professora estruturou a aprendizagem com a intenção de construir pensamento e conhecimento teórico. Desse modo, a professora partiu do interesse de um aluno sobre os elementos presentes na área externa da escola e estruturou atividades que promovessem a compreensão científica desse espaço.

A professora propôs que o aluno observasse a área externa com uma lupa e anotasse em um papel tudo o que via, esse papel seria um mapa. Essa atividade gerou um motivo para que as demais crianças também quisessem procurar os animais presentes naquele espaço. 
Ao explorar importantes dimensões do pensamento teórico, essa situação possibilitou que as crianças gerassem uma representação mental do objeto material, esse objeto criado mentalmente seria capaz de ser substituído por outra representação. Os insetos e a área externa foram transformados em um modelo relacional de insetos e habitats, ao passo que "A construção do desenho torna um modelo mental. O modelo é uma abstração e essa abstração é caracterizado pelas inter-relações entre dependência e independência dos fatores associados com o objeto material" (FLEER, 2010, p. 83, tradução nossa).

Em outro momento o garoto mostrou o mapa que havia feito e marcou um ' $\mathrm{X}$ ' em um determinado lugar e convidou a professora para segui-lo para que juntos encontrassem na área externa o lugar marcado por ele no mapa. Após essas situações, uma série de atividades foram desenvolvidas utilizando o mapa, produzindo e expandindo-o com mais detalhes e conhecimentos acerca dos insetos e seus habitats.

Para Fleer (2010), o garoto foi capaz de estabelecer um modelo que representa o início da construção do conhecimento teórico, já que estabeleceu um modelo relacional entre insetos e habitats.

$\mathrm{Na}$ situação descrita a professora conseguiu introduzir conceitos científicos para o aluno, porque ambos se encontravam no mesmo mundo conceitual, ou seja, a intersubjetividade conceitual e contextual foi contemplada. A professora propôs atividades a partir daquilo que motivava o aluno, trazendo novos conhecimentos (científicos) a partir do seu interesse.

Com essa situação, a professora contribuiu para que se formassem novos motivos, também, nas demais crianças da turma. O que antes podia não ser interesse de todos, com as ações da professora surgiram novos interesses. A intersubjetividade conceitual e contextual também pode ser estabelecida dentro do jogo conceitual, apenas a partir dessa relação que o professor será capaz de entrar na situação imaginária da criança para introduzir novos conceitos científicos.

A brincadeira proporciona ao professor identificar os conhecimentos que as crianças já possuem, assim como seus interesses e aquilo que motiva determinada atividade, além da oportunidade de trazer novos conceitos, como os conceitos científicos no âmbito da Educação Infantil.

Diante do exposto, vemos a proposta do jogo conceitual como uma possibilidade de a brincadeira contribuir com o desenvolvimento conceitual das crianças na Educação Infantil. A percepção consciente dos conceitos, conforme trazido em Fleer (2010), é possível por meio de um sistema baseado em relações específicas de generalização entre os conceitos. 
A partir das ideias apresentadas, é possível destacarmos a importância do professor da Educação Infantil compreender os conceitos cotidianos que a criança possui, e ao passo que esses conceitos são evidenciados, por exemplo, durante a brincadeira, introduzir conceitos científicos para explicar a vida cotidiana e desse modo, também transformá-la, ou seja, o objetivo é que haja uma mudança na relação da criança com sua realidade.

Contudo, a introdução de conceitos científicos na Educação Infantil não ocorre exclusivamente por meio da brincadeira, de acordo com as ideias presentes em Fleer (2010), é possível entendermos que os momentos lúdicos podem contribuir com a aprendizagem científica e o desenvolvimento de outros aspectos da criança, mas que não dependem apenas dessas situações.

A compreensão do conhecimento teórico ajuda a criança na orientação de si própria e gera ferramentas simbólicas que podem ser usadas em outros contextos. Já o pensamento empírico está relacionado com a percepção da realidade e é uma forma de pensamento derivado da atividade sensorial das pessoas em relação ao objeto da realidade, representando a forma primária de pensamento. Essa forma primária de pensamento não ultrapassa o conhecimento imediato da realidade, sem desconsiderar sua importância, já que possibilita a separação dos atributos dos objetos ou fenômenos e sua designação.

Conhecimento e pensamento teórico apoiam a criança na construção de modelos, como no exemplo que a professora contribuiu com a construção do pensamento teórico do garoto. A criança passa a ter consciência do objeto material (no caso do exemplo, o mapa) como uma representação da ação mental. Por meio dessa reflexão consciente do objeto material a criança pode descobrir a essência de um fenômeno.

O mapa, nesse exemplo, representa um modelo mental e relacional, que reproduz ou constrói o objeto em nível ideal. O mapa foi importante para construir o conhecimento relacional e apoiar o pensamento teórico, permitiu que a criança levasse os modelos criados para outros contextos, pensando e agindo de modo diferente.

Ao estabelecer esse conhecimento relacional, a relação da criança com o mundo se modifica, possibilitando que ela estabeleça uma relação diferente com a realidade, contemplando a ideia defendida pelas autoras analisadas de mudança na relação da criança com o mundo em que está inserida. Identificar os conceitos científicos fundamentais permite que o professor estruture o trabalho na Educação Infantil, possibilitando a construção do pensamento e do conhecimento teórico. 
Desse modo, podemos concluir que a proposta do jogo conceitual defendida por Marilyn Fleer desvela a relação dialética entre a imaginação e a cognição, evidenciando que elas devem atuar em unidade.

Compreendendo a situação imaginária como um ato consciente, no jogo conceitual a perspectiva da criança é considerada, mas o professor desempenha um papel ativo na condução e no desenvolvimento do mesmo, que ao trabalhar a imaginação e a cognição em unidade, contemplará também importantes aspectos cognitivos. Portanto, o jogo conceitual traz algumas possibilidades de a brincadeira ser usada no espaço da Educação Infantil para contribuir com a aprendizagem científica da criança.

\section{Considerações finais}

O presente artigo tinha o objetivo de apresentar as contribuições de autores contemporâneos da Teoria Histórico-cultural para a Educação Infantil, destacando o papel da brincadeira e a importância de reconhecermos os diferentes 'ambientes de atividades' aos quais a criança é exposta. Para tanto discorremos, brevemente, sobre os processos de desenvolvimento e aprendizagem da criança, imprescindíveis para pensarmos o papel da atividade lúdica no desenvolvimento da criança, em seguida, apresentamos a proposta do jogo conceitual de Marilyn Fleer.

Notamos que assim como nos materiais analisados, a brincadeira também é vista como central para a Educação Infantil brasileira, referendada em diferentes publicações oficiais produzidos pelo Ministério da Educação tais como: Referencial Curricular Nacional para a Educação Infantil - RCNEI (1998) e as Diretrizes Nacionais para a Educação Infantil DCNEI (2012). Contudo, ao analisarmos tais documentos, notamos que apesar de ser reconhecida a importância da brincadeira na Educação das crianças menores de cinco anos, seu papel, possibilidades e função ainda são pouco exploradas.

Para o RCNEI, a brincadeira é considerada como uma atividade interna da criança, baseada na imaginação e na interpretação da realidade. Assim, o que motiva a criança a brincar também se encontra internamente. Segundo o documento, a intervenção do adulto, no caso o professor, na brincadeira da criança deve ocorrer por meio da observação e seu auxílio consiste na oferta de materiais e de espaços para a brincadeira.

As situações de aprendizagem orientadas pelo professor devem ser estruturadas a partir da escuta das crianças, ou seja, assim como na brincadeira, a aprendizagem no ambiente 
da Educação Infantil depende da própria criança que é capaz de ampliar seus conhecimentos em situações de interação social ou sozinha, ao professor compete o papel de mediador.

Nesses documentos percebemos que a brincadeira é apresentada de maneira superficial, sem o adequado aprofundamento teórico, embora seja apontada como importante para a Educação Infantil.

O RCNEI em particular acaba por colocar a brincadeira no plano subjetivo, obscurecendo suas referências teóricas a respeito do desenvolvimento infantil com o uso do ecletismo (mistura autores de posturas teóricas distintas), gerando confusão na própria compreensão conceitual e também didático metodológica do brincar.

Do modo como a brincadeira é exposta nesses materiais, o professor da Educação Infantil não encontra um respaldo que contribua com o planejamento de suas atividades pedagógicas e contemplem o brincar nas creches e pré-escolas superando o caráter espontaneísta já presente nas salas de aula.

Aliás, a falta desse aparato deve-se ao fato de a concepção defendida por esses materiais não reconhecer a importância do papel do professor, tanto no desenvolvimento da atividade lúdica, quanto nos processos de aprendizagem e de desenvolvimento dos bebês e das crianças menores de cinco anos.

Reforça-se o que Arce (2013) e Hai A. (2018) consideraram os três mitos que precisam ser desconstruídos no interior das escolas de Educação Infantil. O primeiro mito versa justamente a respeito do papel do professor minimizado, chegando por vezes a ser apagado no trabalho pedagógico para que se garanta a livre aprendizagem da criança. $\mathrm{O}$ segundo mito da supremacia da brincadeira livre, espontânea, como algo que libertaria a criança das amarras que escravizam a nós adultos. Por fim, o terceiro mito, pautado na ideia de que ensinar é algo maléfico, ruim, quando falamos de crianças pequenas. Todos esses mitos apoiam-se em uma concepção maturacional e espontaneísta do desenvolvimento infantil e, de certa forma, em uma concepção romântica de infância e criança, que tem dificultado o diálogo da área com os avanços obtidos no entendimento do desenvolvimento humano a partir das ciências cognitivas, das neurosciências e da própria psicologia como um todo.

Diferente da visão abordada nos documentos analisados trouxemos a partir da Teoria Histórico-cultural alguns conceitos e ideias relevantes para pensar, planejar e conduzir a brincadeira no espaço da Educação Infantil.

Entre as contribuições dos autores contemporâneos destacamos a clareza da Educação Infantil estar comprometida com a aprendizagem científica da criança. A partir dessa ideia, 
Marilyn Fleer formula um modelo de brincadeira (conceptual play) como uma possibilidade de a atividade lúdica ser contemplada na Educação Infantil, visando atingir sua finalidade.

Acordamos com Arce (2013) e Hai A. (2018) que o exercício do 'pensamento compartilhado sustentado' se constitui em poderosa ferramenta para o trabalho em sala de aula de Educação Infantil não só durante a atividade da brincadeira, mas durante as demais atividades em sala. É necessário que o professor programe suas atividades diárias de forma a contemplar momentos de atividades estruturadas (atividades de ensino direcionadas pelo professor), atividades em que a criança é encorajada a tomar a inciativa, protagonizando. $\mathrm{O}$ 'pensamento compartilhado sustentado' torna-se momento privilegiado para a construção da protagonização. A brincadeira pensada a partir do que apontamos ganha a importância que possui no processo de desenvolvimento e descoberta do mundo pela criança.

AGRADECIMENTOS: Programa de Pós-Graduação em Educação da Universidade Federal de São Carlos (PPGE - UFSCar) e Coordenação de Aperfeiçoamento de Pessoal de Nível Superior (CAPES).

\section{REFERÊNCIAS}

ARCE, A. Interações ou brincadeiras? Afinal o que é mais importante na educação infantil? E o ensino como fica? In: ARCE, A. (Org.). Interações e brincadeiras na educação infantil. Campinas: Editora Alínea, 2013. p. 17-40.

BRASIL. Ministério da Educação. Secretaria da Educação Básica. Referencial curricular nacional para a educação infantil. Brasília: MEC, 1998. 3 v.

BRASIL. Ministério da Educação. Secretaria da Educação Básica. Diretrizes curriculares nacionais para a educação infantil. Brasília: MEC, 2012.

CHAIKLIN, S. D.; HEDEGAARD, M. Cultural-historical theory and educational practice: some radical-local considerations. Nuances: Estudos sobre Educação, v. 25, n. 1, p. 30-44, 2013.

FLEER, M. Early learning and development: cultural-historical concepts in play. New York: Cambridge University Press, 2010.

FLEER, M.; HEDEGAARD, M. Play, learning, and children's development: everyday life in families and transition to school. New York: Cambridge University Press, 2013.

HAI, A. A. Educação infantil: alimentação, neurociências e tecnologia. Campinas: Editora Alínea, 2018.

HEDEGAARD, M. A cultural-historical approach to learning in classrooms. Outlines: Critical Practice Studies, v. 6, n. 1, p. 21-34, 2004. 
HEDEGAARD, M. The significance of demands and motives across pratices in children's learning and development: an analysis of learning in home and school. Learning, Culture and Social Interaction, v. 3, p. 188-194, 2014.

\section{Como referenciar este artigo}

HAI, A. A.; FARI, M. de O. (Re) significando o brincar na educação infantil a partir da teoria histórico-cultural. Revista Ibero-Americana de Estudos em Educação, Araraquara, v. 15, n. 1 p. $\quad$ 95-109, jan./mar. 2020. e-ISSN: 1982-5587. DOI: https://doi.org/10.21723/riaee.v15i1.12251

Submetido em: 13/02/2019

Revisões requeridas: 26/03/2019

Aprovado em: 20/06/2019

Publicado em: 02/01/2020 